\title{
Carnitine palmitoyl transferase II deficiency, neonatal form
}

INSERM

\section{Source}

INSERM. (1999). Orphanet: an online rare disease and orphan drug data base. Carnitine palmitoyl transferase // deficiency, neonatal form. ORPHA:228308

The neonatal form of carnitine palmitoyltransferase II (CPT II) deficiency (see this term), an inherited disorder that affects mitochondrial oxidation of long chain fatty acids (LCFA), is the lethal form of the disease which presents with multisystem failure. 